\title{
Yabancı Dil Hazırlık Sınıfı Öğrencileri Perspektifinden Pandemi Sürecinde Uzaktan Eğitim: Fenomenolojik Bir Çalışma
}

\author{
Bülent Bay (iD), Nevşehir - Fatih Karataş (D), Nevşehir - Bilal Üstün (D), Nevşehir \\ https://dx.doi.org/10.37583/diyalog.958496
}

$\ddot{O} z$

Araştırmada, yabancı dil hazırlık sınıfı öğrencilerinin pandemi sürecinde geçirmiş̧ oldukları uzaktan eğitim yaşantılarının, uzaktan eğitime ilişkin algılarının ve uzaktan eğitimin teknolojik boyutunun daha geniş bir yapıda incelenmesi amaçlanmaktadır. Araştırma fenomenolojik nitel araştırma olarak tasarlanmıştır. Örneklem seçiminde amaçlı örnekleme yöntemlerin maksimum çeşitlilik örneklemesi tercih edilmiş̧ir. Veriler yarı yapılandırılmış görüşme formu ile yüz yüze görüşme yöntemiyle toplanmıştır. Verilerin analizi için içerik analizi kullanılmıştır. Toplanan veriler bilgisayar tabanlı kelime işlemci programı (NVIVO) kullanılarak tümevarım anlayışılla ilgili temaları türetmek için kodlanmıştır. Kodlar çerçevesinde temalar şekillendirilmiştir. Uzaktan eğitim sürecinde ev ortamının rahatlı̆̆ı ve sağladığı olanakları olumlu; ev ortamındaki dikkat dağıtıcı uyarıcıları ise motivasyon sorunlarına neden olduğu için olumsuz olarak nitelendirmişlerdir.

Anahtar Sözcükler: Uzaktan Eğitim, Pandemi, Fenomenoloji, Yabancı Dil, Hazırlık Ĕgitimi.

\begin{abstract}
Distance Education in the Pandemic Process from the Perspective of Foreign Language Preparatory Class Students: A Phenomenological Study

This study aimed to examine the distance education experiences of foreign language preparatory class students during the pandemic process, their perceptions about distance education and the technological dimension of distance education in a wider perspective. The research is designed as phenomenological qualitative research. Maximum diversity sampling of purposeful sampling methods was preferred in sample selection. The data were collected by face-to-face interview method with semi-structured interview form. Content analysis was used for data analysis. The collected data were coded to derive themes related to inductive understanding using a computer-based word processing program (NVIVO). Themes are shaped within the framework of codes. Students expressed that while the comfort and opportunities of the home environment are regarded as positive in the distance education process, the distracting stimuli in the home environment is stated to be negative as they cause motivation problems.
\end{abstract}

Keywords: distance learning, pandemic, phenomenology, foreign language, preparatory education. 


\section{EXTENDED ABSTRACT}

In the 21st century, the developments in the field of educational technologies and the innovations made in the light of scientific foundations also show their effect on the education systems offered in higher education institutions and offer students new learning opportunities. With the pandemic process, the reflections of the developments in the field of educational technologies become a mandatory need in the field of education. It is seen that countries benefit from information technologies in solving their education problems with the emergency distance education call. Thanks to information technologies, structural changes can be made in education systems (İşman 2011). Therefore, distance education system is seen as the only way out of Pandemic processoriented solutions in the world and in Turkey.

This qualitative study aims to examine the distance education experiences of foreign language preparatory class students during the pandemic process, their perceptions of distance education, the technological dimension of distance education, and the unexpected problems, factors and practices that students encounter in the process. Within the scope of the purpose, answers will be sought for the following research questions:

1. What are the students' views on the positive and negative aspects of distance education?

2. How did distance education during the pandemic process affect students' learning habits?

3. What are the students' opinions about foreign language preparatory education after the pandemic wholly face to face, completely or partly face to face and partly through distance education?

This study is designed as a phenomenological qualitative study. The qualitative phenomenological design in this study, which focuses on the deeper meanings of individuals 'experiences of distance education, is mainly based on rich and detailed explanations of the participants' own words (Marshall / Rossman 2014: 81).

The maximum diversity sampling (Büyüköztürk et al.2018) approach of purposeful sampling methods was preferred in sample selection. In addition to the diversity, all students received distance education for 3 months in the spring semester of the 2019-2020 academic year before participating in the study.

The data for the purpose of the study were collected by face-to-face interview method with semi-structured interview form. The interview method can be seen as a qualitative data collection method that allows the depth of the phenomenon to be addressed as well as obtaining systematic and comparable data among the participants (Patton 1990).

Content analysis was used for data analysis. Each interview lasted approximately 20-30 minutes and a voice recording was used. All voice-recorded interviews were transcribed using a computer-based word processing program 
(NVIVO). Each written text is coded to derive themes related to the understanding of induction. While the first categories were derived, themes were shaped around the emerging codes, and this process continued in detail until the writing stage.

In the framework of Creswell's views, the following strategies were followed to ensure the reliability of the research: (1) consultation with experts after developing the interview programs and making necessary adjustments, (2) pilot implementation before the actual data collection process, (3) in-depth and comprehensive data collection with open-ended interview questions, (4) with the data obtained from the interviews, the detailed writing of the researcher's notes and the discussion of peer information by making conceptual discussions with another researcher who has expertise in qualitative research.

The participants expressed their positive and negative opinions about the distance education process and they stated that it is positive to be at home with their families and to benefit from the comfort of the home environment regarding the concept of family. Distracting stimuli due to environmental conditions in the home environment, on the other hand, were stated to be negative because they cause motivation problems. In addition, it was determined that the participants had positive thoughts about the flexible learning hours provided by the distance education platforms, but they were uncomfortable because they had socialization problems. In addition, it is seen that students have positive views on planning and time management in distance education. The results of the research reveal that the participants do not have any difficulties in accessing distance education platforms and they have positive views on both internet connection and technical equipment.

When the literature on the subject was examined, it was observed that Karakus et al. (2020) reached similar and different results. In the study, the participants negatively evaluated the distance education process that the distance education process negatively affects the social skills of the participants; It was determined that the most common problems faced by the participants were technical problems and lack of equipment, and their motivation in the distance education process was very low. Serçemeli and Kurnaz (2020) also revealed that the participants approached distance education positively due to flexible time and space possibilities, but they could not focus on homework and exams because they did not feel well psychologically, but they did not experience any technical problems with the system.

It is thought that it would be appropriate to prepare course materials suitable for the distance education system within universities and for academic staff to learn how to use distance education systems efficiently with in-service training. In addition, it is thought that conducting future studies with larger sample groups and mixed methods will be useful in order to obtain more accurate and more comprehensive data. 


\section{Giriş}

21.yy'da eğitim teknolojileri alanında yaşanan gelişmeler ve bilimsel temeller ışığında gerçekleştirilen yenilikler, yükseköğretim kurumlarında sunulan eğitim sistemlerinde de etkisini göstererek öğrencilere yeni öğrenme imkânları sunmaktadır. Pandemi süreciyle birlikte eğitim teknolojileri alanındaki gelişmelerin yansımaları eğitim alanında zorunlu bir ihtiyaç haline gelmektedir. OECD ülkelerinin zorunlu sebeplerle yüz yüze eğitime ara vererek eğitim sorunlarını çözmede uzaktan eğitim çağrısıyla bilişim teknolojilerine başvurdukları görülmektedir. Bilişim teknolojileri sayesinde eğitim sistemlerinde yapısal değişikliklere gidilebilmektedir (İşman 2011: 76). Dolayısıyla pandemi sürecinde tek çıkış noktası olarak görülen uzaktan eğitim sistemi, dünyada ve Türkiye'de çözüm odaklı bir seçenek olmuştur.

Yeni teknolojiler sağladıkları kolaylıklar yoluyla öğrenme- öğretme uygulamalarına yön verirken, uzaktan eğitimin bunun en güçlü örneği olmuştur. Özellikle eş zamanlı (senkron) ya da eş zamanlı olmayan (asenkron) öğrenme olanakları bilişim teknolojilerinin uzaktan eğitime kattığı önemli bir üstünlük olmuştur (Aslantaş 2014: 4). Bu üstünlükler 21.yy’ın başlarından itibaren Türk Eğitim Sistemi’nde gerekli görülürken, pandemi süreciyle birlikte zorunluluk haline gelmiş, acil önlemler çerçevesinde uzaktan eğitimi yeniden ele almayı gerektirmiştir (Sayan 2020: 103).

Teknolojinin eğitime entegrasyonu ve sonucunda ortaya çıkan ürünler alanyazında farklı isimlerle anılmaktadır. Sistem için çevrimiçi öğrenme, uzaktan öğrenme, internet tabanlı öğrenme, eşzamanlı - eşzamanlı olmayan öğrenme, bilgisayar destekli öğrenme gibi farklı terimler kullanılırken, ortak ve temel özellikleri olarak internet ağına bağlı, istenilen yerde ve zamanda öğrenme imkânı sunmaları gösterilmektedir (Cojocariu/ Lazar/ Nedeff/ Lazar 2014; Moore/ Kearsey 2011; Saltürk/ Güngör 2020). Bu terimler arasında en çok kabul gören ve kullanılan terimin ise "uzaktan eğitim" olduğu söylenebilir.

Uzaktan eğitim; öğrenen, öğreten ve öğrenme kaynakları arasındaki sınırları ortadan kaldırmaya çalışan, bunu geçekleştirebilmek için mevcut teknolojileri pragmatist bir yaklaşımla kullanan disiplinler arası bir alan (Bozkurt 2017; akt. Sayan 2020: 101) olarak tanımlanabilir. Banar ve Firat'a (2015: 21) göre uzaktan eğitim, "belirli öğretim yönetimi merkezlerinden yürütülen, bireysel öğrenmeyi amaçlayan, öğrenme içeriklerinin özel hazırlanmış materyal ve araçlarla ve çeşitli öğrenme ortamları yoluyla sağlandığı bir öğretim yöntemidir”. Diğer bir bakış açısına göre uzaktan eğitim, "verilerin üretilmesi ve taşınması için başarılı bir stratejinin sürdürüldüğü, yeniliğin en iyi şekilde kullanıldı̆̆g ve öğrencilerin ve eğitmenlerin zaman ve mekân seçme özgürlüklerinin olduğu bir eğitim sistemi olarak da görülebilir” (Gülnar 2003: 36).

21. yüzyılda eğitim teknolojileri alanındaki ilerlemelere bağlı olarak kamusal faaliyetlerdeki hızlı değişimle birlikte, çok sayıda eğitim kuruluşu, uzaktan eğitim için kendi hedeflerini oluşturma ve kendi eğitim stratejilerini geliştirme noktasına gelmiştir. Üniversitelerin birçoğu, özellikle 21.yy'ın başlarından itibaren "ön lisans, lisans ve lisansüstü programlarında derslerin tümü veya bir kısmını uzaktan eğitim uygulamasıyla 
yürütmeye başlamıştır. Bu değişikliğin sebebi, artan öğrenci gereksinimlerine cevap verebilmek, onlara nitelikli bir eğitim sunmak ve çağın gerektirdiği bireysel gelişimi desteklemek olmuştur" (Eroğlu/ Kalaycı 2020: 238).

Yükseköğretim kurumları uzaktan eğitim sistemleri incelendiğinde, 2547 sayılı Yükseköğretim Kanunu ile tanımlanan zorunlu ortak derslerin ve bu dersler arasında yer alan zorunlu yabancı dil dersinin uzaktan eğitim yöntemiyle verildiği örneklerle karşılaşılmaktadır. Yükseköğretim kurumlarında 2013 yılından itibaren ortak derslerin sunumunda tercih edilen uzaktan eğitim sistemi Yükseköğretim Kalite Kurulu (2020) tarafından pandemi sürecinde "acil uzaktan öğretim, acil durum uzaktan öğretim", olarak tanımlanmıştır. Süreçle birlikte Türkiye genelinde zorunlu uygulamaya koyulan uzaktan eğitim sistemi, ortak yabancı dil derslerinin yanında hazırlık sınıfları da dahil olmak üzere bütün yabancı dil derslerinde uygulanan sistem olmuştur.

Uzaktan eğitim kapsamında yabancı dil dersleri, eşzamanlı (senkron) ve eşzamanlı olmayan (asenkron) sistemlerle üniversitelerin sahip oldukları öğrenme yönetim sistemleri (learning management systems-LMS) aracılığıyla gerçekleştirilmektedir. Dolayısıyla eğitim teknolojileri ve uzaktan eğitim deneyimi olan ve olmayan bütün eğitimciler ve öğrenenler, üniversitelerin sunduğu uzaktan eğitim platformlarını kullanmak durumunda kalmıştır.

Yabancı dil öğrenme süreci, dil yeterlilikleri için gerekli bilgi ve becerilerin öngörülemeyen yapısı nedeniyle belki de uzaktan eğitim yoluyla öğrenilmesi en zor alan olarak görülmektedir (Hurd 2006). Öğrencilerin uzaktan öğrenme yöntemini tercih etmelerinin çeşitli nedenleri bulunmaktadır. İlgili literatürde, öğrencilerin aileleriyle birlikte yaşadıkları yerde öğrenime devam edebilme imkânı tercihlerinde öncelikli rol oynamaktadır. Ayrıca bir mesleği icra etmekte olan ve mesai saatleri dışında öğrenimine devam etmek isteyen öğrenciler arasında da bir firsat olarak görülmektedir. Tercihlerini etkileyen diğer başlıca etkenlerin eğitim öğretim maliyetleri, yaşam rolleri, ulaşım ve konaklama gibi çeşitli bireysel değişkenlerden oluştuğu görülmektedir (Altuntaş Y1lmaz 2020; Dikmen/ Bahçeci 2020; Genç/ Gümrükçüoğlu 2020; Karatepe/ Küçükgençay/ Peker 2020; Karakuş/ Ucuzsatar/ Karacaoğlu 2020; Pichette 2009; Serçemeli/ Kurnaz 2020; akt. Doğan 2020: 484).

Pandemi sonrası normalleşme sürecinde, gelişen eğitim teknolojileriyle birlikte uzaktan eğitimin bir acil çözüm seçeneği ya da yüz yüze öğrenmeye destek olmasının dışında, eğitim asıl zemini haline dönüşeceği öngörülmektedir (Telli/ Altun 2020: 27). Hızlı bir uyum süreciyle erken dönem faaliyet raporlarından çıkarılan derslerin, bilimsel araştırmalar temelinde alınan önlemlerin ve bu çerçevede yaşanacak gelişmelerin tüm dünyada bu yöntemin geliştirilmesine hizmet edeceği, yakın gelecekte yeni teknoloji ve sistemlerin de katkılarıyla uzaktan eğitim sisteminin temel öğrenme zemini haline geleceği düşünülmektedir.

Sürecin öğrenci boyutu değerlendirilirken, öğrencilerin bilgiye ulaşıma yollarının neler olduğu, uzaktan eğitimin onların davranışlarında ne tür değişiklikler yarattığı ve yükseköğretimini uzaktan eğitim yoluyla geçiren öğrencilerin bu süreçte neler yaşadıklarının sorgulanması önemli görülmektedir. Dolayısıyla, öğrencilerin kişisel 
yaşantılarının uzaktan eğitim sisteminin eksikliklerini belirlemek ve güçlü yanlarını desteklemek için önemli bulgular sağlayacağı düşünülmektedir.

$\mathrm{Bu}$ nitel çalışma, yabancı dil hazırlık sınıfı öğrencilerinin pandemi sürecinde geçirmiş oldukları uzaktan eğitim yaşantılarını, uzaktan eğitime ilişkin algılarını, uzaktan eğitimin teknolojik boyutunu, öğrencilerin süreçte karşılaştıkları beklenmedik sorunların, faktörlerin ve uygulamaların daha geniş bir yapıda incelenmesini amaçlamaktadır. Amaç çerçevesinde şu araştırma sorularına yanıt aranacaktır:

1. Uzaktan eğitimin olumlu ve olumsuz yönlerine ilişkin öğrenci görüşleri nelerdir?

2. Pandemi sürecinde gerçekleştirilen uzaktan eğitim, öğrencilerin öğrenme alışkanlıklarını nasıl etkilemiştir?

3. Pandemi sonrası yabancı dil hazırlık eğitiminin tamamen yüz yüze, tamamen uzaktan veya kısmen yüz yüze ve kısmen uzaktan eğitim yoluyla yapılması konusunda öğrenci görüşleri nelerdir?

\section{Araştırma Deseni}

$\mathrm{Bu}$ çalışma fenomenolojik nitel bir araştırma olarak tasarlanmıştır. Bireylerin uzaktan eğitime ilişkin deneyimlerine yönelik daha derin anlamlara odaklanan bu çalışmadaki nitel fenomenoloji tasarımı, doğrudan katılımcıların kendi ifadelerine dayanmaktadır (Marshall/ Rossman 2014). Fenomenoloji öncelikle insanların bir fenomen (görüngü) yaşadıklarında bazı ortaklıkları veya özleri olduğu varsayımına dayanır; böylece fenomenologlar bu ortak yapıyı tarif etmeye çalışırlar (Creswell 2007). Fenomenolojik araştırmanın avantajlarından biri, araştırmacıların kişisel deneyimlerini anlamaları için firsatlar sağlamasıdır. Öte yandan bulguların genellemeye uygun olmaması, uygun katılımcıları belirleme zorluğu ve araştırma bulgularının araştırmacının önyargılarından arındırılma zorluğu fenomenolojik desenin sınırlılıkları arasında sayılabilir (Giorgi 1997, akt. Çepni vd. 2018: 441).

\section{Katılımcilar}

Örneklem seçiminde amaçlı örnekleme yöntemlerin maksimum çeşitlilik örneklemesi (Büyüköztürk; Kılıç Çakmak; Akgün; Karadeniz/ Demirel 2018) yaklaşımı tercih edilmiştir. "Maksimum çeşitlilik örneklemesi yaklaşımı birbirinden farklı birey, olay veya kurumlar arasındaki ortak olguları belirlemek, benzerlik veya farklılıkları ortaya çıkarmak amacıyla kullanılır" (Mertkan 2015: 88). Araştırmada kullanılan bu yaklaşım cinsiyet, mezun olunan lise türü, teknoloji okur yazarlığı gibi değişkenlere göre farklılaşan öğrenci profilinin bir araya getirilmesini (Patton 1990) sağlamıştır. Nitel araştırmadaki katılımcı sayısı ile ilgili temel endişeler esas olarak veri doygunluğu ile ilgili olduğundan veri doygunluğunu sağlamak için 10 öğrencinin yeterli olacağ düşünülmüştür. Odak grup görüşmeleri küçük katılımc1 grupları ile yapılır ve tüm katılımcıları ilgilendiren bir konuda tüm katılımcıların görüş, duygu ve beklentilerini 
belirlemeyi amaçlar (Özmen / Karamustafaoğlu, 2019: 66). Fenomenolojik çalışmalarda uygun görülen 7-10 kişilik örneklem büyüklüğü (Yıldırım/ Şimşek 2011: 98) göz önünde bulundurularak araştırmaya 10 öğrenci dâhil edilmiştir. Seçilen öğrenciler (Öğrenciler -A, -B, -C, -D, -E, -F, -G, -H, -I, -J) araştırmaya katılım öncesi 2019-2020 akademik yılı bahar döneminde 3 ay uzaktan eğitim yoluyla öğrenim görmüşlerdir. Katılımcılara ait bilgiler Tablo 1'de sunulmuştur:

\begin{tabular}{|c|c|c|c|c|c|c|}
\hline $\begin{array}{l}\text { Öğrenci ve } \\
\text { kodu }\end{array}$ & Üniversitesi & Bölüm & Sinif & Cinsiyet & Yaş & $\begin{array}{l}\text { Hazırlıkta } \\
\text { geçirdiği } \\
\text { süre }\end{array}$ \\
\hline Öğrenci A & $\begin{array}{lr}\text { Nevşehir } & \text { Hac1 } \\
\text { Bektaş } & \text { Veli } \\
\text { Üniversitesi }\end{array}$ & $\begin{array}{l}\text { Almanca } \\
\text { Öğretmenliği }\end{array}$ & Hazırlık & Kadın & 18 & İlk y1l \\
\hline Öğrenci B & $\begin{array}{lr}\text { Nevşehir } & \text { Hacı } \\
\text { Bektaş } & \text { Veli } \\
\text { Üniversitesi }\end{array}$ & $\begin{array}{l}\text { Almanca } \\
\text { Öğretmenliği }\end{array}$ & Hazırlık & Kadın & 18 & İlk y1l \\
\hline Öğrenci C & $\begin{array}{ll}\text { Nevşehir } & \text { Hac1 } \\
\text { Bektaş } & \text { Veli } \\
\text { Üniversitesi }\end{array}$ & $\begin{array}{l}\text { Almanca } \\
\text { Öğretmenliği }\end{array}$ & Hazırlık & Kadın & 19 & İlk y1l \\
\hline Öğrenci D & $\begin{array}{lr}\text { Nevşehir } & \text { Hac1 } \\
\text { Bektaş } & \text { Veli } \\
\text { Üniversitesi }\end{array}$ & $\begin{array}{l}\text { Almanca } \\
\text { Öğretmenliği }\end{array}$ & Hazırlık & Erkek & 19 & İlk y1l \\
\hline Öğrenci E & $\begin{array}{lr}\text { Nevşehir } & \text { Hac1 } \\
\text { Bektaş } & \text { Veli } \\
\text { Üniversitesi }\end{array}$ & $\begin{array}{l}\text { Almanca } \\
\text { Öğretmenliği }\end{array}$ & Hazırlık & Kadın & 18 & İlk y1l \\
\hline Öğrenci F & $\begin{array}{lr}\text { Nevşehir } & \text { Hac1 } \\
\text { Bektaş } & \text { Veli } \\
\text { Üniversitesi }\end{array}$ & $\begin{array}{l}\text { Almanca } \\
\text { Öğretmenliği }\end{array}$ & Hazırlık & Erkek & 18 & İlk y1l \\
\hline Öğrenci G & $\begin{array}{lr}\text { Nevşehir } & \text { Hac1 } \\
\text { Bektaş } & \text { Veli } \\
\text { Üniversitesi }\end{array}$ & $\begin{array}{l}\text { Almanca } \\
\text { Öğretmenliği }\end{array}$ & Hazırlık & Erkek & 19 & İlk y1l \\
\hline Öğrenci H & $\begin{array}{lr}\text { Nevşehir } & \text { Hac1 } \\
\text { Bektaş } & \text { Veli } \\
\text { Üniversitesi }\end{array}$ & $\begin{array}{l}\text { Almanca } \\
\text { Öğretmenliği }\end{array}$ & Hazırlık & Kadın & 19 & İlk y1l \\
\hline Öğrenci I & $\begin{array}{lr}\text { Nevşehir } & \text { Hac1 } \\
\text { Bektaş } & \text { Veli } \\
\text { Üniversitesi }\end{array}$ & $\begin{array}{l}\text { Almanca } \\
\text { Öğretmenliği }\end{array}$ & Hazırlık & Kadın & 18 & İlk y1l \\
\hline Öğrenci J & $\begin{array}{lr}\text { Nevşehir } & \text { Hac1 } \\
\text { Bektaş } & \text { Veli } \\
\text { Üniversitesi }\end{array}$ & $\begin{array}{l}\text { Almanca } \\
\text { Öğretmenliği }\end{array}$ & Hazırlık & Kadın & 19 & İlk y1l \\
\hline
\end{tabular}

Tablo 1: Kat1lımc1lara Ait Bilgiler 


\section{Veri Toplama Araçları}

Katılımcıların kendi ifadeleriyle veri toplamak ve bir olguya bakış açılarını ortaya çıkarmak için, nitel araştırmacılar büyük ölçüde görüşme verilerine bağımlıdır (Bogdan/ Biklen 2007: 89). Görüşme yönteminin öncelikli avantajı, katılımcıların olgulara ilişkin düşüncelerine odaklanmasıdır (Marshall/ Rossman 2014: 147). Bu çerçevede araştırmanın amacına yönelik veriler yarı yapılandırılmış görüşme formu ile yüz yüze görüşme yöntemiyle toplanmıştır. Görüşme yöntemi katılımcılar arasında sistematik ve karşılaştırılabilir veri elde etmenin yanı sıra fenomenin derinliklerinin ele alınmasına izin veren bir nitel veri toplama yöntemi olarak görülebilir (Patton 1990).

Yarı yapılandırılmış görüşme formu alanyazın ve araştırma soruları temel alınarak araştırmacı tarafından geliştirilmiştir. Form, Türkçe olarak geliştirilmiş ve derinlemesine bilgi elde etmek için açık uçlu sorulardan oluşturulmuştur. Belirsizlikten kaçınmak ve araştırmanın amacı ile görüşme soruları arasında bağlantı kurmak için üç uzmanın görüşüne sunulan veri toplama aracı, alınan geri bildirim temelinde yeniden düzenlenmiştir. Daha sonra, soruların netliğini, uygunluğunu ve etkililiğini sağlamak, soruların akışını ve zamanlamasını değerlendirmek için araştırmanın katılımcıları dışında önceden 5 öğrenciye denenmiştir.

\section{Veri Analizi}

Nitel araştırmalarda veri analizi, verileri yönetilebilir parçalara ayırmayı, kalıpları çözümlemeyi ve elde edilen veri setini sentezlemeyi içermektedir (Bogdan/ Biklen, 2007: 97). Bu çerçevede verilerin analizi için içerik analizi kullanılmıştır. Her görüşme yaklaşık 20-30 dakika arasında sürmüş ve ses kaydı alınmıştır. Bütün ses kayıtlı görüşmeler öncelikle bilgisayar tabanlı kelime işlemci programı (NVIVO) kullanılarak yazılı hale getirilmiştir. Tümevarım anlayışıyla, her bir yazılı metin öncelikle cümle cümle okunarak önemli görülen olay, olgu ve ifadeler (kodlar) belirlenmeye çalışılmıştır. Belirlenen kodlar arasında herhangi bir ilişki olup olmadığını belirlemek için ikinci okuma süreci gerçekleştirilmiştir. Kodlar arası ilişkilerin belirlenmesi ve bu kodların daha üst düzey kavramlar etrafında kümelenmesi (kategorilerin oluşturma) amaçlanmıştır. Oluşturulan kategoriler diğer araştırmacılarla iş birliği içinde değerlendirilerek kuramsal temellere dayandırılmaya (tema oluşturma) çalışılmıştır. Bulguların sunumunda ise bu temalara ilişkin açıklamalara ve katılımcıların kendi ifadelerine yer verilmiştir.

\section{Geçerlik ve Güvenirlik}

Nitel araştırmalarda geçerlik ve güvenirlik her biri çeşitli stratejilerle sağlanabilen birtakım ölçütlerden oluşmaktadır. $\mathrm{Bu}$ ölçütler arasında "inandırıcılık", “aktarılabilirlik", "tutarlık ve doğrulanabilirlik” ölçütleri yer almaktadır (Creswell 2013: 72). Creswell'in görüşleri çerçevesinde araştırmanın güvenilirliği sağlamak için şu stratejiler izlenmiştir: (1) görüşme programlarını geliştirip gerekli düzeltmeler yapıldıktan sonra uzmanlara danışma (2) gerçek veri toplama sürecinden önce pilot 
uygulama gerçekleştirme (3) açık uçlu görüşme sorularıyla derinlemesine ve kapsamlı veri toplama (4) görüşmeden elde edilen verilerle araştırmacı notlarının detaylı yazıya dökümü ve nitel araştırmalarda uzmanlığa sahip başka bir araştırmacı ile kavramsal tartışma süreci gerçekleştirilmiştir.

Geçerlik ve güvenirlik ölçütlerinden biri olan aktarılabilirlik için maksimum çeşitlilik örneklemesi yöntemiyle amaca yönelik katılımcılar seçilmiştir. Ayrıca katılımcıların bağlamı, ilgili özellikleri, veri toplama, analiz ve sonuçları açıklanarak detaylı bilgi sunulmuştur. Son olarak, aktarılabilirliğin yanında araştırmanın doğrulanabilirlik özelliği için araştırma sürecinde ve sonunda nitel bir araştırmacı tarafından sağlanan sürekli geri bildirim yoluyla sonuçların tutarlılığı ve tarafsızlığ kontrol edilmiştir.

\section{Bulgular ve Yorum}

\section{Uzaktan Eğitim Sürecine İlişkin Olumlu ve Olumsuz Çağrışımlar/ Görüşler}

Sonuçlar öğrencilerin uzaktan eğitim ile ilgili hem olumlu hem de olumsuz görüşleri olduğunu ortaya koymaktadır. Öğrenciler uzaktan eğitimin olumlu ve olumsuz yönlerine ilişkin görüşlerini "aile ortamı", "zoraki düzen" ve "teknik donanım" kavramları çerçevesinde değerlendirmektedirler.

\section{Aile Ortamı}

Öğrenciler "aile ortamı” kavramına ilişkin olarak evde aileleriyle birlikte olma ve ev ortamının rahatlığından faydalanma gibi konularını uzaktan eğitimin olumlu yönü olarak değerlendirmektedir. Konuya ilişkin olarak Öğrenciler şunları ifade etmektedir:

\footnotetext{
"Yani böyle yatma kalkma saatleri kendim ayarlıyorum. Daha rahat oluyor. Kahvaltımı yapıyorum. Benim için daha rahattı.” (Öğrenci B)

"Evde olmak benim için ev ortamı açısından tek başına olmak benim için daha rahat. Diğer yönden evde olmak beni ders çalışmaya itiyordu.” (Öğrenci E)

"Babam ve annem sürekli ders çalışırlar sürekli kendilerini geliştirdikleri için. Bizim evde gürültü falan olmuyor, kardeşim de sınava hazırlandı̆̆ 1 için ders çalışıyoruz hepimiz. Yurt ortamında yani yurtta kaldığım için ben daha fazla stres oluyordum ve çalışamıyordum açıkçası.” (Öğrenci G)
}

Ev ortamının olumsuz yönlerine ilişkin öğrenci görüşleri; ev ortamındaki çevresel koşullara bağlı dikkat dağıtıcı uyarıcılar ve bu uyarıcıların odaklanma ve motivasyon sorunlarına neden olmasıyla ilgilidir. Öğrenci D ve Öğrenci F konuya ilişkin olarak şunları ifade etmektedir:

\footnotetext{
"Bir de şey ev ortamında çalışmak ben hiçbir zaman ev ortamında çalışamadım. Evde gürültü eksik olmaz. Yani o yüzden o da beni zorladı.” (Öğrenci D)

"Evde dikkatimi dağıtacak o kadar çok şey var ki. İlk başta yatağım mesela. Yataktan kalkıp masa başına geçmek o kadar zor geliyor ki. Bu da doğal olarak motivasyonumu etkiliyordu." (Öğrenci F)
} 
Ayrıca dikkat dağıtıcı uyarıcılar arasında uzaktan eğitim platformu yoluyla kendilerine sağlanan dijital materyallerini göstermektedirler. Öğrencilerin genel olarak basıll, somut yazılı kaynaklara daha alışkın oldukları dijital kaynaklara adapte olma konusunda sorunlar yaşadıkları ifade edilmektedir. Konuya ilişkin olarak Öğrenci C şu ifadeleri kullanmaktadirlar.

“Olumsuz olarak da uzaktan eğitimde derslerden uzak kaldığımı hissettim. Etrafımda daha çok dikkatimi dağıtan şeyler var. Özellikle bilgisayarda çalışıyor olmak benim için başlı başına dikkat dağıtmam için hani tek araç diyebilirim.” (Öğrenci H)

\section{Zoraki Düzen}

Öğrencilerin yaşadığı düzen alışkanlığı temelde uzaktan eğitimin sağladığı esnek öğrenme saatleri ve öğrenme ortamında sosyalleşme ile ilgilidir. Zoraki düzen kavramı doğrudan öğrencinin ifadesinden seçilerek (Invivo kod) oluşturulmuştur. Kavrama ilişkin öğrenci ifadeleri şöyledir:

\footnotetext{
"Benim için zorunlu bir düzen olması gerekiyor hani her şeyin böyle zoraki bir düzen içinde olması gerekiyor. Birileri ki bu kişiler hocalarımız olabilir, sürekli kontrol altında olmamız ve motivasyonumuzun düşmemesi gerekir" (Öğrenci B)

-Benim için sadece tek olumsuz yönü okula gidememek oldu çünkü okulda daha iyi odaklanıyoruz belli bir süremiz var derste kalma gibi evdeyken sadece işte 5 dakika çalışıp yarım saat mola veriyoruz mesela o huyumu sevmiyorum. (Öğrenci D)

"Evde olmam daha faydalı benim için çünkü evde herkes ders çalışıyor bizim evde... Babam ve annem sürekli ders çalışırlar sürekli kendilerini geliştirdikleri için...kardeşim de sınava hazırlandığı için ders çalışıyoruz hepimiz...benim için sadece tek olumsuz yönü okula gidememek oldu çünkü okulda daha iyi odaklanıyoruz belli bir süremiz var derste kalma gibi evdeyken sadece işte 5 dakika çalışıp yarım saat mola veriyoruz mesela o huyumu sevmiyorum" (Öğrenci J)

“...ben disiplin altındayken daha iyi çalışıyordum...” (Öğrenci G)
}

Uzaktan eğitim platformlarının sağladığı istenilen zamanda tekrardan izleme imkânı, araştırma kapsamında "esnek öğrenme saatleri" kavramı altında ele alınan konuya ilişkin olarak öğrenci görüşlerinin temelde olumlu olduğu dikkati çekmektedir. Örneğin Öğrenci A, Öğrenci C ve Öğrenci F şu ifadeleri kullanmaktadırlar:

"Benim açımdan açıkçası biraz olumlu gibiydi. Yani mesela ben gece çalışmayı daha çok seviyorum. Gündüz pek çalışamıyorum, odaklanamıyorum. Gündüz birçok şeye böyleyim. O yüzden gece genelde çalışıyorum uyumayıp da. Ondan daha verimli oldu benim için." (Öğrenci A)

“...yatma, kalkma ve çalışma [öğrenme] saatlerini ben kendim belirliyorum. Okuldayken böyle bir şey yoktu o yüzden plan program yapmam kolay oldu..." (Öğrenci J)

“...diyordum ki sabah yaparım. İşte sonra sürekli erteliyordum bir bakmışım saat dörtte uyanıyorum. Sonra geriye hiç zaman kalmıyordu.” (Öğrenci B) 
Öğrencilerin sınıf ortamı, ev ortamı, yurt ortamı gibi etkenleri değerlendirdikleri süreçte bu ortamlara ilişkin temel sorunların sosyalleşme kavramı üzerinde temellendiği görülmektedir:

“...ödev konusunda okuldayken daha böyle sıkıntılıydım çünkü aklım fikrim açık konuşayım gezmedeydi ve buradayken evdeyim ve yapacak bir şeyim yok kendi kendime otur ders çalış dediğimden daha fazla üzerine düşebildim.” (Öğrenci I)

"Ben zaten hani böyle dışarı çıkmayı çok seven biriyim. Aynı zamanda böyle ders çalışmayı da çok seven biri değilim yani... [uzaktan eğitim sürecinde] hem evde olup hem ders çalışmak ekstra zor geliyor bana." (Öğrenci F)

- ... [yüz yüze eğitim sürecinde] daha disiplinli çalışıyordum mesela. Buraya [uzaktan eğitimde ev ortamına] geldiğimden beri kendime pek fazla bir şey katamadım. Çok boş vaktim var, ödevleri yapmak hoşuma gidiyor çünkü ders çalışmıyorum. Almancadan da kopmak istemiyorum ama bu ödevlere ek herhangi bir şey de yapmıyorum." (Öğrenci D)

\section{Teknik Donanım}

Üniversitelerin öğrencilere sağlamış olduğu uzaktan eğitim platformları ve bu platformlara bağlanmada gerek duyulan internet bağlantısı, bilgisayar vb. teknik donanım konusunda öğrencilerin genel anlamda çok fazla sorun yaşamadıkları bulgulanmıştır.

\section{2. Öğrenme Alışkanlıklarına İlişskin Endişe ve Görüşler}

Öğrencilerin yaşadığı öğrenme alışkanlıklarına ilişkin endişe ve görüşlerinin; bireysel ve grupla öğrenme alışkanlıkları, kaynaklara erişim, yeni öğrenme alışkanlıkları, öğrenme önyargıları ve zaman yönetimi kavramları çerçevesinde şekillendiği görülmektedir.

\section{Bireysel ve Grupla Öğrenme Alışkanlıkları}

Öğrencilerin, grup çalışmaları ile tartışma ortamlarını yüz yüze ve uzaktan eğitim kapsamında karşılaştırdıkları görülmektedir. Kıyaslama sürecinde bu tür öğrenme ortamlarının yüz yüze eğitimde daha etkili olduğu yönünde eğilim göstermektedirler. Diğer bir ifadeyle öğrenciler, grupla çalışma ve karşılıklı tartışma sürecini uzaktan eğitimin olumsuz yönü olarak algılamaktadırlar. Konuya ilişkin olarak öğrenciler şunları ifade etmektedir:

\footnotetext{
"Okuldaki o yani bu uzaktan eğitimde okuldaki gibi şey olamıyorsun yani o ortamı istesen de bulamiyorsun. O yüzden derslerden de uzak kaldım...- bireysel olarak çalışmak zorundayım uzakta olduğum için. Ama okuldayken kütüphaneye arkadaşlarla gitmek de motivasyon oluyordu derse katılmak açısından.” (Öğrenci B)

“...ben sınıf ortamında daha iyi olduğunu düşünüyorum. Çünkü mesela çok fazla böyle farklı farklı yorumlarımız oluyor. İşte istişare yaptığımız oluyor konular hakkında. Dolayısıyla daha iyi olduğunu düşünüyorum. Aynı zamanda grup çalışmaları falan
} 
gayet faydalı oluyordu. Hani mesela benim bir eksiğim varsa bir arkadaşım onu tamamlıyordu veya benim karşıdaki arkadaşımın bir eksiği varsa ben ona yardımcı oluyordum. Daha iyi oluyordu.” (Öğrenci G)

\section{Kaynaklara Erișim}

Öğrencilere uzaktan eğitim sürecinde kendilerine sağlanan ya da tedarik etmeleri istenen öğrenme materyalleri konusunda görüşleri sorulmuştur. Öğrenciler kendilerine uzaktan eğitim platformu üzerinden video derslerin ve dijital kaynakların sunulduğunu ve bu kaynakların da çok yeterli olmadığını ifade etmektedirler. Dijital kaynaklar yerine basılı, somut kaynaklardan daha iyi öğrendiklerini, dijital kaynakların odaklanma sorunlarına neden olduğunu ifade etmektedirler. Bu bağlamda öğrencilerin şu ifadeleri dikkati çekmektedir:

\footnotetext{
"Kaynak çok sınırlı. Mesela bir şey aradığım zaman bulmak çok zor oluyor hele ki internetten arıyorsak elimizde de kaynak yoksa ki düzgün kaynak bulmak da çok zor internetten..." (Öğrenci B)

“...ben sevmiyorum her dakika elimde telefonla veya bilgisayarda bir şey okumayı. Daha çok elimde kâğıdı hissetmek istiyorum yani." (Öğrenci F)

“...daha doğrusu şöyle siz PDF olarak atıyorsunuz ya da bilmem ne şeyler. Ama mesela ben böyle ben de dokunmak istiyorum, üstüne bir karalamak istiyorum, çizmek istiyorum, o şekilde soruyu çözmek istiyorum.” (Öğrenci C)
}

Kaynak türü olarak öğretmenlerle iletişime geçerek soru sorma, fikir alışverişinde bulunma konusunda ise öğrencilerin çok sorun yaşamadığ görülmektedir. Ancak öğretmenlerini rahatsız etme çekincesi ile iletişime geçip geçmeme konusunda tereddüt yaşadıkları anlaşılmaktadır. Örneğin, Öğrenci E ve Öğrenci A şunları ifade etmektedir:

“Öğretmenlerle iletişime geçme yani sizlerle iletişim kurarken bir sıkıntı yaşamadım... size bir soruyu rahat soruyoruz ama yüz yüze konuşmak gibi olmuyor.” (Öğrenci E)

"En ufak soruları bile soramayacağım bilgilerin olmaması uzaktan eğitimin olumsuz bir yönü... sürekli hocalarıma sormak zorunda kalıyorum bu da uzaktan olunca, sizi rahatsız etmiş oluyorum. Yani ben en azından öyle görüyorum.” (Öğrenci H)

\section{Yeni Öğrenme Alışkanlıkları}

Uzaktan eğitimin öğrenme alışkanlıklarına etkileri sorgulandığında öğrenci görüşlerinin farklılaştı̆̆ı görülmektedir. Bazı öğrenciler yeni öğrenme yollarını keşfettiklerini, araştırma yoluyla bireysel olarak da öğrenebilme potansiyellerinin olduğunu ve bu potansiyeli de uzaktan eğitim sürecinde keşfettiklerini ifade etmektedirler. Öğrenciler, keşfettikleri yeni öğrenme alışkanlıklarına ilişkin şu örnekleri ve ifadeleri kullanmaktadırlar:

"Ben gramer [dilbilgisi] konusunda ilerlediğimi düşünüyorum. Çünkü farklı bir yöntem buldum. Kendim kitap hazırlıyormuş gibi gramer [dilbilgisi] kitabı hazırlyyorum, örnekleri kendim yapıyorum, işte kendi cümlelerimle açıklamaya çalışıyorum bazı şeyleri...” (Öğrenci A) 
"Kendim böyle bir defter oluşturdum. Gramer [dilbilgisi] defteri. Bulduğum sitelerdeki örnekleri yazmayı tercih ettim defterimde. Daha çok aklımda kalsın diye. Çünkü benim görsel hafızam daha kuvvetli. Youtube'dan birkaç sokak röportajları izlemeye başladım. Hem İngilizce hem Almanca alt yazısı vardı. Oradan hem İngilizcemin hem Almancamın dinleme kısmının geliştiğini düşünüyorum.” (Öğrenci F)

"Araştırırken Google Çeviride [sitesinde] şey yapıyordum [cümlenin] Türkçesini yazıyordum, Almancaya çeviriyordum, Almanca sitelerde araştırma yapıp sonra konu hakkında kendi kafamda özet çıkartıp Almanca bir şeyler yapmaya çalışıyordum." (Öğrenci J)

“...internetten böyle videolar izleyerek kendime bir şeyler katmaya çalıştım. Başka şeyler de öğrenmemi sağladı. Dizi falan da açıp izliyorum, oradaki söylenenleri böyle tekrar etmeye çalışıyorum. Diziler dışında, daha belirgin bir konu üzerinde konuştukları için sokak röportajları izlemeye başladım. Dineleme-anlama açısından daha faydalı oluyor." (Öğrenci E)

\section{Öğrenme Önyargıları}

Öğrenme alışkanlıklarına ilişkin görüşlerinin sorgulandığı görüşme dökümlerinin satır aralarında, öğrencilerin özellikle öğrenme alışkanlıklarına ilişkin birtakım önyargılarının ve inançlarının olduğu dikkati çekmektedir. Bu önyargı ve inançlar doğrudan öğrenci ifadeleriyle aşağıda aktarılmıştır:

“Önceleri dinleme, konuşma ve grameri [dilbilgisini] okulda öğrenmemiz gerektiğini düşündüğüm için sadece onlarda sıkıntı yaşıyorum. Ama kendim de öğrenebiliyormuşum meğer. Sonra sonra anladım ancak bunları.” (Öğrenci J)

"Mesela ben daha öncesinde asla tek başıma öğrenebileceğimi düşünmüyordum, mutlaka bana birilerinin anlatması gerektiğini düşünüyordum ama bu süreçte fark ettim ki bir şeyleri kendim de çok iyi seviyede olmasa bile anlayabiliyormuşum ...bir süre sonra gerçekten Almanca sitelere girip o şekilde araştırmaya başladım ve bu bana daha fazla faydası oldu, tek başıma da araştırarak öğrenebileceğimi anladım.” (Öğrenci D)

\section{Zaman Yönetimi}

Uzaktan eğitimde planlama ve zaman yönetimi konusunda öğrenciler olumlu görüşler belirtmektedirler. Aile ortamında, Pandemi sürecinin zorunlulukları ve yasakları da göz önünde bulundurulduğunda boş zaman yönetimini farklı şekillerde değerlendirdikleri görülmektedir. Konuya ilişkin olarak Öğrenci $\mathrm{E}$ ve Öğrenci $\mathrm{C}$ şu ifadeleri kullanmaktadırlar:

"Ben evde motivasyonumun boş zamanlardan kaynaklı biraz daha arttığını düşünüyorum. Evde çok boş zamanım var ve ne yapabilirim, benim için en iyi yöntem ders çalışmak. O yüzden burada daha fazla kendimi geliştirdiğimi düşünüyorum.” (Öğrenci E)

"Çok zamanım olduğu için kendim kitap hazırlıyormuş gibi gramer [dilbilgisi] kitabı hazırlıyorum, örnekleri kendim yapıyorum, işte kendi cümlelerimle açıklamaya çalışıyorum bazı şeyleri... uzaktan eğitim olmasaydı bunları yine yapabilir miydim bilemiyorum ama orada olsaydım [üniversitede yüz yüze eğitim] sanırım buradaki [aile 
ortamında uzaktan eğitim] rahatlıktan dolayı yapıyorum, orada [yüz yüze eğitimde] buna pek zamanım yeter miydi bilmiyorum.” (Öğrenci C)

\section{Bütünleşik Sistem Uygulamasına ve Değerlendirme Sürecine İlişkin Görüş̧ler}

Öğrencilere, pandemiden sonra yabancı dil eğitiminde, yüz yüze ve uzaktan öğrenme sistemlerinin bir arada kullanılabileceği bütünleşik bir sistemin geliştirilerek uygulanıp uygulanamayacağı sorulmaktadır. Bu tür bir sistemin yanı sıra değerlendirme sürecinin nasıl olması gerektiği konusunda öğrenci görüşleri alınmaya çalış1lmıştır. Öğrenci görüşleri; bütünleşik sistem uygulaması ve değerlendirme kavramları altında ele alınmıştır.

\section{Bütünleşik Sistem Uygulaması}

Öğrencilerden yabancı dil eğitimini; tamamen yüz yüze, tamamen uzaktan, kısmen yüz yüze ve kısmen uzaktan olmak üzere farklı sistem uygulamaları konusunda değerlendirmeleri ve yüzde oranları vermeleri istenmektedir. Diğer bir ifadeyle sonraki y1llarda tercih edilebilecek olası karma sistemde (yüz yüze ve uzaktan eğitim siteminin birlikte kullanılması) dil becerilerinin hangi oranda yüz yüze, hangi oranda uzaktan eğitimle verilmesi gerektiğine ilişkin görüşleri sorulmuştur. Ulaşılan bulgularda öğrencilerin özellikle dilbilgisi konusunda birtakım önyargılarının ve endişelerinin olduğu anlaşılmaktadır. Öğrenciler, temel dil becerileri çerçevesinde (okuma, dinleme, konuşma ve yazma) değişen yüzdeler ifade ederken, görüşme yapılan öğrencilerin tamamı dilbilgisi derslerinin yüz yüze olması gerektiğini, uzaktan eğitimle gerçekleştirilmesinin verimli olamayacağını belirtmişlerdir. Konuya ilişkin olarak öğrencilerden bazılarının görüşleri şu şekildedir:

\footnotetext{
“...bence gramerin tamamının yüz yüze olması gerekiyor. Online olarak halledilebileceğini pek düşünmüyorum.” (Öğrenci B)

“...gramerin hepsinin yüz yüze olmasını savunuyorum ama diğerlerinin uzaktan eğitimle çözüleceğini düşünüyorum.” (Öğrenci D)

“...yazmada bir sıkıntımız olmadı, dinlemede bir sıkıntımız olmadı, okumada bir sıkıntımız olmadı, tek bizi endişelendiren gramer konusu oldu. Onları bulmamız, onlara çalışmamız; ondaki eksikliğimizden dolayı diğgerlerinde hata yaptık.” (Öğrenci A)

“...bende gramer haricinde diğerlerinin uzaktan eğitimle yapılması, yani yapılabilir bence de. Ama gramer yüz yüze olmalı diye düşünüyorum.” (Öğrenci G)

“...gramer dersleri yüz yüze olmalı, okuma dersinin de üç saatini okulda yapsak üç saatinde uzaktan eğitimle yapsak daha iyi olur diye düşünüyorum... Gramer [dilbilgisi] kesinlikle yüz yüze olmalı.” (Öğrenci E)

“...bence gramer kesinlikle yüz yüze olmalı...” (Öğrenci I)
}

Yabanc1 dil eğitiminin tamamen yüz yüze veya tamamen uzaktan; ya da kısmen yüz yüze, kısmen uzaktan eğitimle verilmesi halinde oranların nasıl olması gerektiği konusundaki öğrenci görüşleri Tablo 2'de sunulmaktadır: 


\begin{tabular}{|c|c|c|c|c|c|c|c|c|c|c|}
\hline & \multicolumn{2}{|c|}{ Dilbilgisi } & \multicolumn{2}{|c|}{ Okuma } & \multicolumn{2}{|c|}{ Dinleme } & \multicolumn{2}{|c|}{ Konuşma } & \multicolumn{2}{|c|}{ Yazma } \\
\hline & 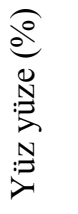 & 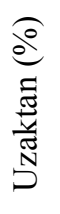 & 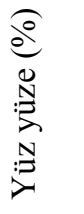 & 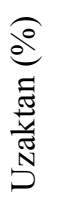 & 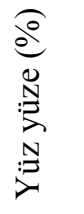 & 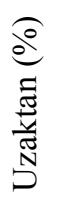 & 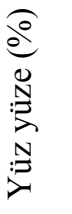 & 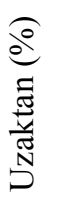 & 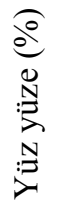 & 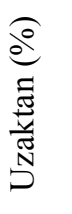 \\
\hline Öğrenci A & 100 & 0 & 30 & 70 & 50 & 50 & 25 & 75 & 100 & 0 \\
\hline Öğrenci B & 100 & 0 & 25 & 75 & 0 & 100 & 100 & 0 & 100 & 0 \\
\hline Öğrenci C & 100 & 0 & 0 & 100 & 0 & 100 & 100 & 0 & 0 & 100 \\
\hline Öğrenci D & 100 & 0 & 0 & 100 & 0 & 100 & 70 & 30 & 0 & 100 \\
\hline Öğrenci E & 100 & 0 & 0 & 100 & 0 & 100 & 40 & 70 & 0 & 100 \\
\hline Öğrenci F & 100 & 0 & 50 & 50 & 50 & 50 & 100 & 0 & 75 & 25 \\
\hline Öğrenci G & 100 & 0 & 0 & 100 & 30 & 70 & 50 & 50 & 0 & 100 \\
\hline Öğrenci H & 100 & 0 & 50 & 50 & 100 & 0 & 50 & 50 & 0 & 100 \\
\hline Öğrenci I & 100 & 0 & 40 & 60 & 25 & 75 & 100 & 0 & 50 & 50 \\
\hline Öğrenci J & 100 & 0 & 100 & 0 & 50 & 50 & 25 & 75 & 0 & 100 \\
\hline Ortalama & 100 & 0 & 29,5 & 70,5 & 30,5 & 69,5 & 66 & 34 & 32,5 & 67,5 \\
\hline
\end{tabular}

Tablo 2: Yabancı Dil Eğitiminde Bütünleşik Sistem Uygulaması Oranları

Tablo 2'e göre öğrenciler, bütünleşik uygulama sisteminde dilbilgisi alanı için \%100 yüz yüze, okuma becerisi için \%29,5 yüz yüze, \%70,5 uzaktan; dinleme becerisi için $\% .30,5$ yüz yüze, $\% 69,5$ uzaktan; konuşma becerisi için \%66 yüz yüze, $\% 44$ uzaktan ve yazma becerisi için de \%32,5 yüz yüze \%67,5 oranlarında sistem planlaması yapılması gerektiğini belirtmektedirler.

\section{Uzaktan Eğitimde Ölçme ve Değerlendirme}

Değerlendirme sürecine ilişkin olarak, öğrencilerin büyük çoğunluğunun sinav güvenliği konusunda kaygılarının olduğu, uzaktan eğitimle kendilerine sunulan ölçme ve değerlendirme türü ve araçları (performans ödevi, çevrimiçi sınav) dışında görüş bildiremedikleri dikkati çekmektedir. Sınav güvenliğine odaklanan öğrenci görüşleri ise şu şekildedir:

“...uzaktan eğitim sınavları kesinlikle test şeklinde olmamalı.” (Öğrenci B)

“...cep telefonu diye bir şey var yani oradan da kopya çekilebilir o yüzden

katılmıyorum bence şeye kesinlikle online [çevrimiçi] sınava...” (Öğrenci A)

"Kimin daha iyi yaptığını değil kimin daha iyi kopya çekebildiğini gösteriyor diye düşünüyorum...” (Öğrenci $\mathrm{H}$ ) 


\begin{abstract}
"Bence herkesin aynı verimi almasını düşünüyorsak ve arada bir haksızlık olmaması gerekiyor bu yüzden ya ödev ya da yüz yüze yani online [çevrimiçi] sözlü olması gerektiğini düşünüyorum.” (Öğrenci C)

“...bence de online sınavın olması güvenlik açısından iyi değil.” (Öğrenci F)
\end{abstract}

\title{
Sonuç ve Tartışma
}

$\mathrm{Bu}$ çalışmada yabancı dil hazırlık sınıfı öğrencilerinin pandemi sürecinde uzaktan eğitime yönelik görüşleri değerlendirilmiştir.

Katılımcıların, uzaktan eğitim sürecine ilişkin olumlu ve olumsuz görüşlerini ifade ederlerken aile kavramına ilişkin olarak evde aileleriyle birlikte olmayı ve ev ortamının rahatlığından faydalanmayı olumlu; ev ortamındaki çevresel koşullara bağlı dikkat dağıııcı uyarıcıları ise motivasyon sorunlarına neden olduğu için olumsuz olarak nitelendirdikleri belirlenmiştir. Ayrıca katılımcıların uzaktan eğitim platformlarının sağlamış olduğu esnek öğrenme saatleri hakkında olumlu düşüncelere sahip oldukları, fakat sosyalleşme problemi yaşadıklarından dolayı rahatsızlık duydukları saptanmıştır. Ayrıca öğrencilerin uzaktan eğitimde planlama ve zaman yönetimi konusunda olumlu görüşlere sahip oldukları görülmektedir. Araştırma sonuçları, katılımcıların uzaktan eğitim platformlarına erişim sıkıntısı yaşamadıklarını; internet bağlantı hızlarının ve teknik donanımlarının derslere katılım noktasında yeterli olduğunu ortaya koymaktadır. Konu ile ilgili literatür incelendiğinde Karakuş ve arkadaşlarının (2020: 240) benzer ve farklı sonuçlara ulaştıkları gözlemlenmiştir. Karakuş ve arkadaşları yaptıkları çalışmalarında katılımcıların uzaktan eğitim sürecini olumsuz değerlendirdikleri; uzaktan eğitim sürecinin katılımcıların sosyal becerilerini olumsuz etkilediğini; katılımcıların en sık yaşadıkları problemlerin teknik aksaklıklar ve donanım eksikliği olduğu ve uzaktan eğitim sürecinde motivasyonlarının çok düşük olduğu belirlenmiştir. Serçemeli ve Kurnaz (2020: 52) da çalı̧̧alarından elde ettikleri bulgularda katılımcıların esnek zaman ve mekân olanaklarından dolayı uzaktan eğitime olumlu yaklaştıklarını fakat psikolojik olarak kendilerini iyi hissetmediklerinden dolayı ödevlere ve sınavlara odaklanamadıkların fakat buna rağmen sistemle ilgili teknik bir problem ise yaşamadıklarını ortaya koymuşlardır. Genç ve Gümrükçüoğlu (2020: 421) da öğrencilerin, uzaktan eğitim sisteminden vakit tasarrufu ve derslere kolay ulaşım bağlamında memnun olduklarını fakat sosyalleşemedikleri için yüz yüze eğitimi tercih ettiklerini; ayrıca öğrencilerin uzaktan eğitim sürecinde etraflarında dikkat dağıtıcı unsurların çok fazla olmasının derslere motive olmalarını engellediğini ve öğrencilerin yaklaşık yarısının uzaktan eğitim sürecinde başarılarının düştüğünü ve uzaktan eğitim yoluyla verilen derslerden verim alamadıklarını ve yüz yüze eğitimin önemini kavradıkları sonucuna ulaşmışlardır. Zan ve Umut Zan (2020: 1387-1390) da Genç ve Gümrükçüoğlu'nu desteklemekte, "uzaktan eğitim sisteminde en temel gereksinimin ders çalışmak için sessiz bir alana sahip olunması gerektiğini" ve "uzaktan eğitim sistemi sürecinde ev içi koşulların olumsuz etkiler" doğurduğunu ifade etmektedirler. Altuntaş Yılmaz (2020: 19) da uzaktan eğitim sistemini yukarıda adı geçen araştırmacılara benzer bir yaklaşımla ele almakta, "uzaktan eğitimin birçok açıdan 
olumlu yanlarının olmasına karşın uygulanmasında ve öğrenmenin sağlanması açısından bazı sınırlılıkları olduğunu, bu sınırlılıkların öğrencinin okul ortamındaki gibi sosyalleşme olanağına sahip olamaması, uygulama gerektiren derslerin uzaktan eğitim platformları ile sağlanamaması, yüz yüze eğitimin az olması sebebiyle derslere ilginin ve motivasyonun düşmesi, teknolojik cihazları kullanmada sıkıntı yaşayan öğrencilerin bilgiye ulaşmada zorluk yaşaması" gibi noktalara değinmektedir. Dikmen ve Bahçeci (2020: 93) konuya üniversitelerin altyapı sistemleri bağlamında yaklaşmakta, yapmış oldukları çalışmalarında "Türkiye'deki üniversitelerin çoğunluğunun uzaktan eğitim altyapısına sahip olduğunu" ifade etmektedirler. Can ise "yükseköğretim kurumlarının Anadolu Üniversitesi, İstanbul Üniversitesi ve Atatürk Üniversitesi gibi üniversitelerin sahip olduğu deneyimlerden faydalanması gerektiğini ve kendilerini altyapı, donanım ve içerik vb. yönlerden geliştirmeleri” gerektiğini vurgulamaktadır (2020: 33-34).

Araştırmada, öğrencilerin öğrenme alışkanlıkları konusunda sınıf ortamında geçirdikleri tartışma ortamlarını daha yararlı buldukları, uzaktan eğitim yoluyla gerçekleşen etkileşimin sınıftaki etkileşime göre zayıf kaldığı belirlenmiştir. Ayrıca öğrenciler, video derslerin ve dijital materyallerin yetersizliğine vurgu yaparak motive olmakta zorlandıklarını ifade etmişlerdir. Bazı öğrencilerin uzaktan eğitime yönelik önyargılara sahip olduğu, bazı öğrencilerin ise uzaktan eğitim yoluyla yeni öğrenme yolları keşfettikleri ve bireysel öğrenme yoluyla potansiyellerini ortaya çıkardıkları tespit edilmiştir. Her ne kadar bazı öğrenciler video dersleri ve dijital materyalleri yetersiz bulduklarını belirtseler de ders sorumlusu hocalara ulaşmada bir sorun yaşamadıklarını, yalnızca hocayla iletişime geçip geçmeme konusunda tereddüt yaşadıklarını ifade emişlerdir. Konu ile ilgili yapılmış araştırmalar incelendiğinde Can da benzer sonuçlara ulaşmış, "erişime açılan materyallerin tamamının basılı materyallerden oluştuğunu, etkileşimli veya alternatif öğrenme kaynaklarına ihtiyaç duyulduğunu; özellikle yükseköğretim düzeyinde uzaktan eğitim merkezlerinin ders içeriklerinin, senkron eğitim ve altyapı başta olmak üzere pek çok yönden yeterli hazırlığın bulunmadığını” saptamıştır (2020: 33). Benzer şekilde Karadağ ve Yücel yaptıkları araştırmalarında "çalışmaya katılan lisans öğrencilerinin uzaktan eğitim sürecinde özellikle dijital içerik/ öğretim materyallerinden memnuniyetsizlik duyduklarını (2020: 190); Genç ve Gümrükçüoğlu, "uzaktan eğitim materyallerinden yararlanan öğrencilerinin oranının yaklaşık \%28 olduğunu" ve "uzaktan eğitim sürecinde temin edilen ve online sisteme yüklenen ders materyallerinin öğrenciyi tatmin etmekten uzak olduğunu" (2020: 419); Eroğlu ve Kalaycı ise "uzaktan eğitim uygulamasının öğrencilerin sorularına cevap bulamadığı bir öğretim uygulaması olduğunu" ve "ders içeriklerinin üniversite düzeyine göre basit ve yetersiz olduğunu" ifade etmişlerdir (2020: 259-260). Özyürek ve arkadaşları "uzaktan eğitim sürecinde öğrencilerin öğretim elemanları ile iletişim konusunda sorun yaşamadıklarını" ifade etmişlerdir (2020: akt. Karatepe/ Küçükgençay/ Peker: 1271). Zan ve Umut Zan da çalışmasında benzer bir sonuca ulaşarak "öğrencilerin farklı iletişim araçlarını kullanarak istediklerinde akademisyenlerine ulaştıklarını ve çoğunlukla üniversitenin iletişim sistemini tercih ettiklerini” ve "öğrencilerden bireysel öğrenme ihtiyaçlarını karşılayabilmeleri için ilgi ve alakalarını belirleyerek öğrenme ortamlarını oluşturma 
çabası içinde olmalarının beklendiği” belirtmişlerdir (2020: 1388-1389). Buluk ve Eşitti'nin ise çalışmalarının sonucunda farklı bir sonuca ulaştıkları, "katılımcıların öğretim elemanları ile iletişim etkinliklerinin iyi olmadığı” gözlenmiştir (2020: 294).

Araştırmada yer alan katılımcıların, uzaktan eğitim süreci bittiğinde derslerin bütünleşik sistemle işlenebileceği konusunda olumlu yaklaşım gösterdikleri belirlenmiştir. Katılımcılar okuma, yazma, dinleme ve konuşma becerisi derslerinin kısmen de olsa uzaktan eğitim yoluyla verilebileceğini, fakat dilbilgisi derslerinin tamamının yüz yüze işlenmesi gerektiğini ifade etmişlerdir. Buna sebep olarak da dilbilgisi derslerinin uzaktan eğitim yoluyla verimli ve anlaşılır olmadığını göstermişlerdir. Araştırmada yer alan katılımcıların, uzaktan eğitim süreci bittiğinde derslerin bütünleşik sistemle işlenebileceği konusuna olumlu yaklaşım gösterdikleri belirlenmiştir. Katılımcılar, okuma, dinleme ve yazma becerisi derslerinin yaklaşık \%70'inin; konuşma becerisi dersinin ise yaklaşık \%30'unun uzaktan eğitim yoluyla işlenebileceğini ifade etmişlerdir. Katılımcılar, dilbilgisi derslerinin tamamının yüz yüze işlenmesi gerektiğini, bu dersin uzaktan eğitim yoluyla verimli ve anlaşılır olmadığını belirtmişlerdir. İlgili literatür incelendiğinde, Karakuş ve arkadaşlarının (2020: 239) "öğretmenlerin uzaktan eğitim sürecinin en çok dinleme, en az ise yazma becerisine katkı sağladığını düşündükleri sonucuna ulaştıkları" görülmektedir. Ayrıca katılımcıların, özellikle sınav güvenliği konusunda kaygı taşıdıkları gözlenmiştir. Genç ve Gümrükçüoğlu (2020: 419) da çalışmalarında benzer bir bulguya ulaşmış, "araştırmaya katılan öğrencilerden sınavların hakkaniyetli olduğunu söyleyenlerin oranının yaklaşık \%25 olduğu” nu tespit etmişlerdir. Eroğlu ve Kalayc1 (2020: 260) da "öğrencilerin, değerlendirme boyutunda yaşadıkları problemin sınavların güçlük ve ayırt ediciliğinin düşük olması kaynaklı" olduğunu belirtmişlerdir. Can (2020: 34) ise "pek çok yükseköğretim kurumunun çevrimiçi sınav uygulama esaslarının bulunmadığını, çevrimiçi sınav uygulamalarına ilişkin yasal ve pedagojik düzenlemelere ihtiyaç olduğunu" ifade etmektedir.

Uzaktan eğitim sisteminin daha verimli hale gelebilmesi için öğrencilere ve eğiticiler arasında kaynak paylaşımını kolaylaştıracak sistemlerin geliştirilmesinin; öğrencilerin uzaktan eğitim sistemini daha rahat kullanabilmeleri için dijital okur yazarlık veya bilgisayar eğitiminin hazırlık sınıfından itibaren verilmesinin; üniversiteler bünyesinde uzaktan eğitim sistemine uygun ders materyallerinin hazırlanmasının ve akademik personelin hizmet içi eğitimlerle uzaktan eğitim sistemlerini verimli şekilde kullanabilmeyi öğrenmelerinin yerinde olacağ düşünülmektedir. Ayrıca ileride yapılacak çalışmaların daha geniş örneklem gruplarıyla ve karma yöntemlerle yapılmasının daha doğru ve daha kapsamlı veriler elde edebilme adına yararlı olacağı düşünülmektedir. 


\section{Kaynakça}

Altuntaş Yılmaz, Buket (2020): Yükseköğretim kurumlarında Covid-19 pandemisi sürecinde uygulanan uzaktan eğitim durumu hakkında öğrencilerin tutumlarının araştırılması: Fizyoterapi ve rehabilitasyon bölümü örneği. Necmettin Erbakan Üniversitesi Sağllk Bilimleri Fakültesi Dergisi, $3(1), 15-20$.

Aslantaş, Tankut (2014): Uzaktan eğitim, uzaktan eğitim teknolojileri ve Türkiye'de bir uygulama. Erişim adresi: http://www. tankutaslantas.com/wp-content/uploads/2014/04/UzaktanE\% C4\% 9Fitim-Uzaktan-E\% C4\% 9Fitim-Teknolojileri-ve, 2014.

Banar, Kerim/ Fırat, Mehmet (2015): Bütüncül bir bakıştan açık ve uzaktan eğitim: Türkiye özeli, Yeğitek Uzaktan Eğitim Özel Sayıs1, 18-23. Ankara: MEB Yenilik ve Eğitim Teknolojileri Genel Müdürlüğü.

Beldarrain, Yoany (2006): Distance education trends: Integrating new technologies to foster student interaction and collaboration. Distance Education, 27(2), 139-153.

Bogdan, Robert/ Biklen, Sari Knopp (2007): Research for education: An introduction to theories and methods. Boston: Allyn \& Bacon.

Buluk, Buket/ Eşitti, Bekir (2020): Koronavirüs (Covid-19) sürecinde uzaktan eğitimin turizm lisans öğrencileri tarafından değerlendirilmesi. Journal of Awareness, 5(3), 285-298.

Büyüköztürk, Şener/ Kılıç Çakmak, Ebru/ Akgün, Özcan Erkan/ Karadeniz, Şirin/ Demirel, Funda (2018): Bilimsel araştırma yöntemleri (24. baskı). Ankara: Pegem Akademi.

Can, Ertuğ (2020): Coronaviriü (Covis-19) pandemisi ve pedagojik yansımaları: Türkiye'de açık ve uzaktan eğitim uygulamaları. Açıköğretim Uygulamaları ve Araştırma Dergisi, 6(2), 11-53.

Cojocariu, Venera-Mihaela/ Lazar, Iulia/ Nedeff, Valentin/ Lazar, Gabriel (2014): SWOT anlysis of e-learning educational services from the perspective of their beneficiaries. Procedia-Social and Behavioral Sciences, 116, 1999-2003.

Creswell, John William (2007): Qualitative inquiry and research design: Choosing among five approaches. Thousand Oaks, CA: Sage.

Creswell, John William (2013): Nitel araştırma yöntemleri: Beş yaklaşıma göre nitel araştırma ve araştırma deseni (3. Baskl). Ankara: Siyasal Kitabevi.

Çepni, Osman/ Aydın, Fatih/ Kılınç, Ali Çağatay (2018): Erasmus Programına Katılan Öğrencilerin Yaşadıkları Sorunlar ve Çözüm Önerileri: Fenomenolojik Bir Araştırma. Journal of Higher Education \& Science/Yüksekögretim ve Bilim Dergisi, 12(3), 436-450.

Dikmen, Semih/ Bahçeci, Ferhat (2020): Covid-19 pandemi sürecinde yükseköğretim kurumlarının uzaktan eğitime yönelik stratejileri: Fırat Üniversitesi örneği. Turkish Journal of Educational Studies, 7(2), 78-98.

Doğan, Yunus (2020): Üniversite öğrencilerinin uzaktan çevrim-içi yabancı dil öğrenmeye yönelik görüşlerinin değerlendirilmesi. Türk Ĕ̆itim Bilimleri Dergisi, 18(1), 483-504.

Eroğlu, Fahriye/ Kalaycı, Nurdan (2020): Üniversitelerdeki zorunlu ortak derslerden yabancı dil dersinin uzaktan eğitim uygulamasının değerlendirilmesi. Türk Ĕ̆itim Bilimleri Dergisi, 18(1), 236-265.

Genç, Muhammet Fatih/ Gümrükçüoğlu, Süleyman (2020): Koronavirüs (Covid-19) sürecinde İlahiyat Fakültesi öğrencilerinin uzaktan eğitime bakışları. Turkish Studies, 15(4), 403-422.

Gülnar, Birol (2003): Bilgisayar ve internet destekli uzaktan eğitim programlarının tasarım, geliştirme ve değerlendirme aşamaları (Suzep örneği). Yayımlanmamış Doktora Tezi. Konya: Selçuk Üniversitesi Sosyal Bilimler Enstitüsü. 
Hurd, Stella (2006): Individual learner differences and distance language learning: An overview. RTVU ELT Express, 12(4), 1-27.

İşman, Aytekin (2011): Uzaktan Eğitim. Ankara: Pegem Akademi Yayıncılı.

Karadă̆, Engin/ Yücel, Cemil (2020): Yeni tip Koronavirüs pandemisi döneminde üniversitelerde uzaktan eğitim: Lisans öğrencileri kapsamında bir değerlendirme çalışması. Yükseköğretim Dergisi, 10(2), 181-192.

Karakuş, Neslihan/ Ucuzsatar, Nil/ Karacaoğlu, Mehmet Önder/ Esendemir, Nurullah/ Bayraktar, Dilek (2020): Türkçe öğretmeni adaylarının uzaktan eğitime yönelik görüşleri. RumeliDE Dil ve Edebiyat Araştırmaları Dergisi, (19), 220-241.

Karatepe, Fadimana/ Küçükgençay, Naci/ Peker, Bilge (2020). Öğretmen adayları senkron uzaktan eğitime nasıl bakıyor? Bir anket çalışması. Journal of Social and Humanities Sciences Research, $7(53), 1262-1274$.

Marshall, Catherine/ Rossman, Gretchen (2014): Designing qualitative research. Sage publications.

Mertkan, Şefika (2015). Karma araştırma tasarımı. Ankara: Pegem Akademi.

Moore, Michael/ Kearsley, Greg (2011): Distance education: A systems view of online learning. Cengage Learning.

Özmen, Haluk/ Karamustafaoğlu, Orhan (2019): Eğitimde Araştırma Yöntemleri. Ankara: Pegem Akademi.

Patton, Michael Quinn (1990): Qualitative evaluation and research methods. Newbury Park, CA: Sage.

Saltürk, Aylin/ Güngör, Cumhur (2020): Üniversite Öğrencilerinin Gözünden Covid-19 Pandemisinde Uzaktan Eğitime Geçiş Deneyimi. Adlyaman Üniversitesi Sosyal Bilimler Enstitüsü Dergisi, 36, $137-174$.

Sayan, Hamiyet (2020): COVİD-19 Pandemisi Sürecinde Öğretim Elemanlarının Uzaktan Eğitime İlişkin Görüşlerinin Değerlendirilmesi. AJIT-e: Bilişim Teknolojileri Online Dergisi, 11(42), 100122.

Serçemeli, Murat/ Kurnaz, Ersin (2020): Covid-19 pandemi döneminde öğrencilerin uzaktan eğitim ve uzaktan muhasebe eğitimine yönelik bakış açıları üzerine bir araştırma. Uluslararası Sosyal Bilimler Akademik Araştırmalar Dergisi, 4(1), 40-53.

Telli, Sahure Gonca/ Altun, Deniz (2020): Coronavirüs ve çevrimiçi (online) eğitimin önlenemeyen yükselişi. Üniversite Araştırmaları Dergisi, 3(1), 25-34.

Yıldırım, Ali/ Şimşek, Hasan (2011): Sosyal bilimlerde nitel araştırma yöntemleri. Ankara: Seçkin Yayıncılik.

Yükseköğretim Kalite Kurulu (2020): Pandemi Döneminde Uzaktan Eğitim. https://portal.yokak.gov.tr/makale/pandemi-doneminde-uzaktan-egitim/ adresinden 13 Ocak 2021 tarihinde erişilmiştir.

Zan, Nuray/ Umut Zan, Burcu (2020): Koronavirüs ile acil durumda eğitim: Türkiye'nin farklı bölgelerinden uzaktan eğitim sistemine dahil olan Edebiyat Fakültesi öğrencilerine genel bakış. Turkish Studies, 15(4), 1367-1394. 